\title{
Rapid electrochemical identification of pathogenic Candida species
}

\section{Correspondence \\ Alan Wheals \\ bssaew@bath.ac.uk}

Received 6 January 2009

Accepted 2 June 2009

\author{
Alastair Muir, ${ }^{1}$ A. Toby A. Jenkins, ${ }^{2}$ Gordon Forrest, ${ }^{3}$ John Clarkson ${ }^{3}$ \\ and Alan Wheals ${ }^{1}$ \\ ${ }^{1}$ Department of Biology and Biochemistry, University of Bath, Bath BA2 7AY, UK \\ ${ }^{2}$ Department of Chemistry, University of Bath, Bath BA2 7AY, UK \\ ${ }^{3}$ Atlas Genetics Ltd, White Horse Industrial Park, Trowbridge, UK
}

\begin{abstract}
This study describes the development of a novel assay to detect fungal DNA and identify the most clinically relevant invasive human pathogenic fungi to the species level using oligonucleotide probes, labelled with electrochemically active groups, and solid-state electrodes. A panfungal probe designed against the 18S rRNA gene region, capable of detecting all fungal pathogens tested, and species-specific probes, designed against the ITS2 region for detection of the five Candida species most commonly encountered in the clinical setting (Candida albicans, Candida glabrata, Candida parapsilosis species complex, Candida krusei and Candida tropicalis), are described. When tested with PCR-amplified DNA from both type and clinical strains of the relevant species, the probes were able to positively identify the relevant fungi, indicated by production of a current significantly elevated above the background reading. No cross-reactivity was observed with any of the species-specific probes when compared with nine non-target Candida species or in the presence of human DNA equivalent to an equal number of ITS2 targets. The panfungal probe gave results that were similarly positive against 15 other fungal species and also did not cross-react with human DNA. The limit of detection of the assay was shown to be approximately 1 genome equivalent for all probes using extracted genomic DNA.
\end{abstract}

\section{INTRODUCTION}

Increasingly, fungal species, particularly of the genera Candida, Aspergillus and Cryptococcus, are responsible for life-threatening invasive conditions in immunocompromised patients. A recent study in Denmark reported that $98 \%$ of fungaemia episodes were caused by Candida species (Arendrup et al., 2008). Badiee et al. (2009) found in a southern Iranian hospital that two Aspergillus species were responsible for $27.3 \%$ of invasive fungal infections in a sample of patients who had undergone a kidney transplant or chemotherapy. Data from 134 study sites gathered by the ARTEMIS DISK Global Antifungal Surveillance Study showed that Cryptococcus species were the most common non-Candida yeast species implicated in invasive fungal infections (Pfaller et al., 2009). In the UK between 2004 and 2006, the Mycology Research Laboratory identified 3033 yeast isolates and found that Candida albicans alone accounted for $39.3 \%$ of these, and together with five other species, Candida glabrata, Candida parapsilosis, Candida tropicalis, Candida lusitaniae and Candida krusei, collectively accounted for approximately $86 \%$ of isolates (Linton et al., 2007). Up to 20 infrequently encountered Candida species such as Candida rugosa and

Abbreviation: DPV, differential pulse voltammetry.
Candida guilliermondii have also been implicated in candidaemia (Kao et al., 1999; Hajjeh et al., 2004).

The mortality of candidaemia is high (Tortorano et al., 2004; Horn et al., 2007) due to the immunocompromised status of the infected patients, although co-morbidities exist in these patients making the causal link between Candida infection and mortality difficult to establish. Rapid detection of fungal species is essential, as a delay in initiation of therapy by even $24 \mathrm{~h}$ can lead to a significant increase in mortality (Garey et al., 2006), whilst a varying spectrum of susceptibility to antifungal agents exhibited by clinically relevant fungi means that identification to the species level is essential for appropriate treatment.

Current methods of detection and identification of fungi lack sensitivity and are time-consuming. There are now several techniques based on molecular detection of fungal DNA following PCR amplification that have increased sensitivity and which are more rapid than culture, including the use of radiolabelled species-specific probes and Southern blotting of PCR products (van Deventer et al., 1995), enzyme immunoassays (Fujita et al., 1995; Shin et al., 1997; Clancy et al., 2008) and, more recently, numerous assays developed using fluorescent methods (Baskova et al., 2007; Metwally et al., 2007; Hata et al., 2008; Lau et al., 2008). 
Hillier et al. (2004) showed that electrochemical detection of target DNA was possible using ferrocene-labelled oligonucleotide probes and a suitable double-strandspecific exonuclease to digest the bound probe. This resulted in the release of a ferrocene-labelled mononucleotide, which could be oxidized at an electrode and the current produced measured using differential pulse voltammetry (DPV). In outline, following digestion, the released mononucleotide-ferrocene molecules are free to diffuse to an electrode surface where a potential is applied to the electrode. This causes oxidation of the ferrocene molecule and produces a measurable current which is proportional to the amount of mononucleotide-ferrocene present at the electrode surface, which in turn is proportional to the amount of target DNA that was initially present. Any undigested oligonucleotide that is present cannot diffuse freely to the electrode surface, or is inhibited in electron transfer, and so oxidation of the ferrocene label and production of current is minimal when the sample is free of DNA or contains non-target DNA. We have shown here that, with the addition of a PCR step and the design of species-specific probes, this procedure can detect DNA from a wide range of fungal pathogens and identify the five most clinically relevant species of Candida to the species level by using a single panfungal probe and five species-specific probes.

\section{METHODS}

Culture acquisition. The following type strains were obtained from the Centraal Bureau voor Schimmelcultures (CBS): Candida albicans CBS $562^{\mathrm{T}}$, Candida parapsilosis CBS $604^{\mathrm{T}}$, Candida glabrata CBS $138^{\mathrm{T}}$, Candida tropicalis CBS $94^{\mathrm{T}}$, Candida krusei CBS $573^{\mathrm{T}}$, Candida lusitaniae CBS $4413^{\mathrm{T}}$, Candida famata CBS $767^{\mathrm{T}}$, Candida dubliniensis CBS $7987^{\mathrm{T}}$, Candida kefyr CBS $834^{\mathrm{T}}$ and Candida guilliermondii CBS $566^{\mathrm{T}}$. Clinical strains were acquired from the culture collection at the University of Bath and from other donors. All species used had their identity confirmed by sequencing of the ITS2 region. All yeasts were cultured on yeast-peptone-dextrose (YPD) agar at $28{ }^{\circ} \mathrm{C}$ for $48 \mathrm{~h}$ and stored at $4{ }^{\circ} \mathrm{C}$ before being transferred to liquid YPD medium with $10 \%$ glycerol and stored at $-20{ }^{\circ} \mathrm{C}$ until DNA was extracted. Filamentous fungi were cultured on potato dextrose agar (PDA; Oxoid).

DNA extraction. A Qiagen DNeasy extraction kit was used for all extractions and the manufacturer's protocol was followed with some modifications that were appropriate for treatment of fungal material. In brief, approximately $5 \times 10^{6}$ yeast cells in liquid medium were collected by centrifugation at $8400 \mathrm{~g}$ for $10 \mathrm{~min}$ and the cell pellet was resuspended in $500 \mu \mathrm{l}$ lyticase lysis buffer comprising lyticase from Arthrobacter luteus (10 $\mathrm{U} \mathrm{ml}^{-1}$; Sigma), $50 \mathrm{mM}$ Tris/HCl (pH 7.5), $10 \mathrm{mM}$ EDTA and $28 \mathrm{mM} \beta$-mercaptoethanol. For filamentous fungi, the PDA was flooded with $1 \mathrm{ml}$ of a sterile solution of $0.9 \%$ saline and agitated to transfer fungal material to the solution. The saline was then collected, centrifuged and resuspended in lyticase buffer as above. Lyticase digestion was performed at $37{ }^{\circ} \mathrm{C}$ for $30 \mathrm{~min}$. Spheroplasts were collected by centrifugation at $8400 \mathrm{~g}$ for $10 \mathrm{~min}$ and resuspended in $180 \mu \mathrm{l}$ buffer ATL. Proteinase K solution $(20 \mu \mathrm{l})$ provided in the kit was added to the suspension and a $45 \mathrm{~min}$ incubation at $55{ }^{\circ} \mathrm{C}$ was carried out. After this treatment, $200 \mu \mathrm{l}$ buffer AL and $200 \mu \mathrm{l}$ absolute ethanol were added to the samples and mixed thoroughly. Following the addition of ethanol, the samples were left on ice for $30 \mathrm{~min}$ to increase precipitation of DNA and enhance final yield. The samples were then placed in silica-based spin columns and wash steps with $500 \mu \mathrm{l}$ buffer AW1 and AW2 were applied following the manufacturer's instructions. DNA was then eluted twice from each column using $50 \mu$ l elution buffer for each elution and a single $1.5 \mathrm{ml}$ tube was used to collect both eluates. Estimates of DNA concentration were obtained by spectrophotometry, and dilutions of extracted genomic DNA were prepared with a solution of $10 \mathrm{mM}$ Tris/ $\mathrm{HCl}(\mathrm{pH} 9.0) / 0.5 \mathrm{mM}$ EDTA for use in the limit of detection assays. All DNA was stored at $-20{ }^{\circ} \mathrm{C}$.

Primers and probes. Fungal universal primers ITS3 and ITS4 (White et al., 1990) were obtained from Sigma. The primers amplified a region between the $3^{\prime}$ end of the 5.8S rRNA gene and the $5^{\prime}$ end of the $28 \mathrm{~S}$ rRNA gene, which encompassed the ITS2 region. The novel primers ITS3.3 and ITS4.2 were designed manually in order to demonstrate the limit of detection of the assay and these also amplified the ITS2 region between the $5.8 \mathrm{~S}$ and $28 \mathrm{~S}$ rRNA genes. The sequences of probes that targeted this region for species-specific detection of Candida species were obtained from Shin et al. (1999). These species-specific probes were targeted to Candida albicans (CA PR), Candida tropicalis (CT PR), Candida parapsilosis species complex (CP PR), Candida glabrata (CG PR) and Candida krusei (CK PR), and were synthesized and labelled at the $5^{\prime}$ terminal nucleotide with a proprietary ferrocene compound (ATDBio). CA PR and CG PR were found to produce unsatisfactory results and so improved probes, CA PR3 and CG PR3, were designed manually for the detection of Candida albicans and Candida glabrata, respectively. The panfungal probe (PanF PR) was designed manually by analysing a matrix of $18 \mathrm{~S}$ rRNA gene sequences that had been obtained from GenBank and identifying an appropriate target site for a probe. This probe was then subjected to a BLAST search (Altschul et al., 1997) against a database containing fungal $18 \mathrm{~S}$ rRNA gene sequences, as well as human, plasmodium and trypanosome sequences, to ensure that it had high similarity to all of the fungal sequences but not to the non-target sequences. The same matrix was then used to identify potential primers to amplify the area surrounding the PanF PR target site. Following PCR trials, the forward primer Fungal18sF2 and the reverse primer Fungal18sR4 were chosen for use with the PanF PR probe. Table 1 lists the probe and primer sequences.

Assessing cross-reactivity of probes using bioinformatics. A matrix of fungal ITS2 sequences was constructed using MEGA version 4.0 software (Tamura et al., 2007) and used as a database for a BLAST query with each of the Candida species-specific probes. Any nontarget species that were found to have $\geqslant 60 \%$ identity to any of the species-specific probes were used in assays to test for cross-reactivity.

PCR using Candida species DNA. All PCRs were performed in a Peltier PTC thermal cycler (MJ Research). Asymmetric PCR conditions using a $5: 1$ ratio of reverse: forward primers were used to generate an excess of single-stranded target DNA for the assay. For testing probe specificity and the ability to detect clinical isolates, these PCRs were set up in triplicate and, for all probes except CA PR3, were carried out in a volume of $30 \mu \mathrm{l}$ containing the following reagents: PCR buffer [10 mM Tris/HCl (pH 9.0), $50 \mathrm{mM} \mathrm{KCl,} 1.5 \mathrm{mM} \mathrm{MgCl}_{2}$; GE Healthcare], $100 \mathrm{nM}$ forward primer, $500 \mathrm{nM}$ reverse primer, $0.15 \mathrm{mM}$ each dNTP, $1 \mathrm{U}$ IllustraTaq DNA polymerase (GE Healthcare) and $2 \mu \mathrm{l}$ extracted DNA corresponding to $10-100 \mathrm{ng}$. The remaining volume was made up to $30 \mu$ with molecular-grade water (DNase-, RNase- and protease-free, $0.1 \mu \mathrm{m}$ filtered; Sigma). PCRs to amplify the ITS2 region for sequencing were carried out as above but in a reaction volume of $50 \mu \mathrm{l}$ and symmetrical PCR conditions were used (500 nM each primer). Sequencing reactions were carried out by MWG and BLAST searches were performed against the GenBank sequence database to confirm the identity of the fungal isolates. For amplification of Candida albicans DNA for the 
Table 1. Novel primer and internal probe sequences used in the electrochemical detection assay

All probes had a diferrocene label attached by a carbon linker molecule to the $5^{\prime}$ terminal nucleotide.

\begin{tabular}{|c|c|c|c|c|}
\hline Primer/probe & Sequence $\left(5^{\prime} \rightarrow 3^{\prime}\right)$ & $\begin{array}{c}\text { GenBank accession } \\
\text { no. }\end{array}$ & $\begin{array}{c}\text { Binding position } \\
\text { (nt) }\end{array}$ & Species detected \\
\hline \multicolumn{5}{|l|}{ Primers } \\
\hline ITS3.3 & TGCCTGTTTGAGCGTCATTTC & FJ662407 & $315-335$ & \\
\hline ITS4.2 & AGTCCTACCTGATTTGAGG & FJ662407 & $509-491$ & \\
\hline Fungal18sF2 & GCCATGCATGTCTAAGTATAA & X99399 & $45-65$ & \\
\hline Fungal18sR4 & CCTCGTTAAGGGATTTAAATTGT & X99399 & $535-513$ & \\
\hline \multicolumn{5}{|l|}{ Probes } \\
\hline CA PR3 & ATCGCTTTGACAATGGCTTA & AB032172 & 373-392 & C. albicans \\
\hline CT PR & CAAAACGCTTATTTTGCTAGTGGCC & AY282528 & $224-248$ & C. tropicalis \\
\hline CP PR & GGTACAAACTCCAAAACTTCTTCCA & AJ635316 & $413-437$ & C. parapsilosis \\
\hline CG PR3 & TCAGTATGTGGGACACGAGCGCAAG & AB032177 & $632-656$ & C. glabrata \\
\hline CK PR & AGTGGCCCGAGCGAACTAGACTTTT & EU266565 & $363-387$ & C. krusei \\
\hline PanF PR & GGTGATTCATAATAACTTTTCG & AY497766 & $99-120$ & All fungi \\
\hline
\end{tabular}

electrochemical assay, the buffer used comprised $10 \mathrm{mM}$ Tris/ $\mathrm{HCl}$ ( $\mathrm{pH} 8.3) / 50 \mathrm{mM} \mathrm{KCl} . \mathrm{MgCl}_{2}$ was added separately to give a final concentration of $3 \mathrm{mM}$. The lower $\mathrm{pH}$ and higher concentration of $\mathrm{MgCl}_{2}$ were used because these provided better conditions for activity of the T7 exonuclease used in the assay (Kerr \& Sadowski, 1972). The amplification conditions were: $94{ }^{\circ} \mathrm{C}$ for $1 \mathrm{~min} ; 40$ cycles of $94{ }^{\circ} \mathrm{C}$ for $20 \mathrm{~s}, 55^{\circ} \mathrm{C}$ for $20 \mathrm{~s}$ and $72{ }^{\circ} \mathrm{C}$ for $20 \mathrm{~s}$; and $72{ }^{\circ} \mathrm{C}$ for $3 \mathrm{~min}$. The PCR conditions for the limit of detection assay were as above except that a $50 \mu \mathrm{l}$ reaction volume was used. The PCR buffer was prepared in house and provided the reaction with $10 \mathrm{mM}$ Tris/ $\mathrm{HCl}(\mathrm{pH} 8.3)$ and $50 \mathrm{mM} \mathrm{KCl}$. $\mathrm{MgCl}_{2}$ was added separately to give a concentration in the reaction of $3 \mathrm{mM}$ and $2.5 \mathrm{U}$ Jumpstar Taq DNA polymerase (Sigma) was used. Serial dilutions $(1 \mu \mathrm{l})$ of genomic DNA over 2 orders of magnitude were added to give a range of template DNA from $3.7 \mathrm{pg}$ to $37 \mathrm{fg}$, which was equivalent to a range of $\sim 100$ genomes to $\sim 1$ genome of a diploid Candida species based on estimates of fungal genome size reported by Kullman et al. (2005). For the assay with Candida glabrata DNA, $1.05 \mathrm{pg}-10.5$ fg genomic DNA was used, corresponding to $<100$ genomes to $<1$ genome (Kullman et al., 2005). The amplification conditions were: $95{ }^{\circ} \mathrm{C}$ for $1 \mathrm{~min} ; 40$ cycles of $94{ }^{\circ} \mathrm{C}$ for $30 \mathrm{~s}, 58{ }^{\circ} \mathrm{C}$ for $30 \mathrm{~s}$ and $72{ }^{\circ} \mathrm{C}$ for $1 \mathrm{~min}$; and $72{ }^{\circ} \mathrm{C}$ for $3 \mathrm{~min}$. A $10 \mu \mathrm{l}$ aliquot of the PCR products was visualized on an ethidium bromide-stained agarose gel to check for contamination and to confirm the presence of amplified DNA (data not shown). For all assays, $20 \mu \mathrm{l}$ PCR product was used for the electrochemical assay.

Electrochemical assay. The probe mix for the assay contained the following reagents: $3 \mu \mathrm{M}$ of the relevant probe and $10 \mathrm{U}$ T7 exonuclease (New England Biolabs) made up to $5 \mu \mathrm{l}$ with molecular-grade water (Sigma). The probe mix was added to the remaining $20 \mu \mathrm{l} \mathrm{PCR}$ product and incubated for $20 \mathrm{~min}$ at $37^{\circ} \mathrm{C}$. When incubation was complete, $20 \mu \mathrm{l}$ of the probe reaction mix was pipetted onto screen-printed carbon electrodes with a silver/silver chloride reference electrode. The assays testing probe specificity and detection of clinical strains were performed using electrodes manufactured by Gwent Electronic Materials and those testing the limit of detection were performed using electrodes manufactured by G. M. Nameplate. The observed current due to oxidation of the released ferrocene-labelled nucleotide following DPV was measured using a potentiostat (Autolab PGSTAT30; EcoChemie) and dedicated software (GPES version 4.9; EcoChemie). DPV measurements allowed the measurement of low concentrations of electroactive species by effectively subtracting capacitive charging current which can other- wise mask low concentration measurements. The following settings were used: modulation time $0.04 \mathrm{~s}$, interval time $0.1 \mathrm{~s}$, initial procedure $-0.1 \mathrm{~V}$, end potential $0.5 \mathrm{~V}$, step potential $0.003 \mathrm{~V}$, modulation amplitude $0.05 \mathrm{~V}$.

\section{RESULTS AND DISCUSSION}

\section{Results of PCR and sequencing}

The primer pairs ITS3/ITS4 and ITS3.3/ITS4.2 were able to amplify the ITS2 region in all of the species tested, whilst the Fungal18sF2/Fungal18sR4 primer pair was able to successfully amplify a region in the $18 \mathrm{~S}$ rRNA gene in all species tested. An amplicon was produced when both symmetrical and asymmetrical conditions were used and the size of each amplicon corresponded to the expected size based on sequence information (data not shown).

\section{Testing probe specificity with Candida type strains}

BLAST searches against the fungal ITS2 sequence matrix using the sequences of the species-specific probes revealed that five species contained regions with $\geqslant 60 \%$ similarity to the CG PR probe binding site. Assays using the CG PR probe and these species displayed cross-reactivity (data not shown) and as a result the probe CG PR3 was designed, which had no significant similarity to any of the fungal species in the matrix. The CA PR3 probe displayed $70 \%$ similarity to a region in the ITS2 sequence of Candida dubliniensis, but, when tested, the current produced was a similar value to the other non-target currents (Table 2). None of the other probes produced alignments with significant similarity to non-target species.

To test the specificity of the species-specific probes experimentally, an assay was performed with each of the probes using DNA extracted from 10 type strains of Candida species (Table 2) and a DNA-free sample. The first 
Table 2. Mean currents \pm SD obtained with the five species-specific Candida probes when tested against the target species and nine other non-target Candida species

The mean background current calculated for each probe was subtracted from all of the results for that probe. The mean currents produced by the probes against their target species are highlighted in bold.

\begin{tabular}{|c|c|c|c|c|c|}
\hline \multirow[t]{2}{*}{ Species } & \multicolumn{5}{|c|}{ Mean current minus background current values obtained with species-specific probes (nA) } \\
\hline & CA PR3 & CP PR & CG PR3 & CT PR & CK PR \\
\hline C. parapsilosis & $-3.2 \pm 8.3$ & $96.2 \pm 19.6$ & $-4.7 \pm 5.7$ & $6.6 \pm 3.4$ & $-1.4 \pm 9.2$ \\
\hline C. glabrata & $3.1 \pm 7.3$ & $-1.7 \pm 7.2$ & $73.8 \pm 16.8$ & $9.6 \pm 9.1$ & $-0.4 \pm 6.4$ \\
\hline C. tropicalis & $-1.6 \pm 5.9$ & $-5.7 \pm 6.2$ & $-7.7 \pm 5.4$ & $135.0 \pm 7.0$ & $-1.5 \pm 8.2$ \\
\hline C. dubliniensis & $1.1 \pm 3.8$ & $3.8 \pm 6.7$ & $-5.8 \pm 7.7$ & $5.6 \pm 5.3$ & $1.2 \pm 7.4$ \\
\hline C. kefyr & $0.4 \pm 7.8$ & $-3.1 \pm 6.9$ & $-3.5 \pm 6.2$ & $3.9 \pm 5.3$ & $9.1 \pm 6.7$ \\
\hline C. famata & $-5.5 \pm 1.3$ & $1.3 \pm 13.1$ & $4.6 \pm 6.0$ & $6.3 \pm 4.9$ & $-2.3 \pm 7.8$ \\
\hline C. guilliermondii & $0.1 \pm 4.2$ & $3.9 \pm 10.2$ & $7.6 \pm 11.3$ & $4.2 \pm 8.5$ & $1.9 \pm 7.3$ \\
\hline
\end{tabular}

Candida albicans-specific probe, CA PR, did not allow significant discrimination between target- and non-targetcontaining samples (data not shown), and small changes to the reagents used for PCR (higher $\mathrm{MgCl}_{2}$ concentration and lower $\mathrm{pH}$ ) as well as the design of a new probe, CA PR3, were implemented to improve the conditions of the assay and so obtain much higher currents with target DNA. After this redesign, all of the species-specific probes were found to be able to discriminate between their target species and nine non-target Candida species. Peak current heights were measured, examples of which are shown with the CT PR probe (Fig. 1). Fig. 2 shows examples of the mean background currents from DNA-free samples produced in assays with two of the Candida speciesspecific probes. When the probes were present in the assay without target DNA, background currents were produced and found to vary between probes, with the highest values being produced by CA PR3 and the lowest values by CK $\mathrm{PR}$. This mean background current was subtracted from the mean values obtained from the target DNA-containing samples for each probe.

\section{Testing DNA from clinical Candida isolates}

To test the ability of the species-specific probes to detect clinical strains of Candida, PCRs were performed with DNA from four clinical isolates of the relevant species as well as from the type strain. DNA-free samples were also included to produce background values for each probe. All species-specific probes were able to detect DNA from clinical isolates (Fig. 3). The adjusted mean values (sample mean current minus background mean current) reported for the CK PR probe were relatively low compared with the values reported in Table 2 and with the values produced by the other probes in Fig. 3. This was caused by considerably lower currents than expected being produced by both the target-containing samples and by the DNA-free samples. However, after adjustment, the mean currents remained high enough to indicate positive detection of the target DNA.

\section{Testing the panfungal probe against a range of pathogenic fungi}

A panfungal probe, PanF PR, was tested against DNA from a range of commonly occurring fungi in invasive infections together with three additional opportunistic fungal pathogens and one non-pathogenic fungal species (Fig. 4). The fungal DNA tested produced mean currents that ranged from $88.83 \pm 15.44 \mathrm{nA}$ for Cryptococcus victoriae to $356.03 \pm 35.76 \mathrm{nA}$ for Cryptococcus gattii.

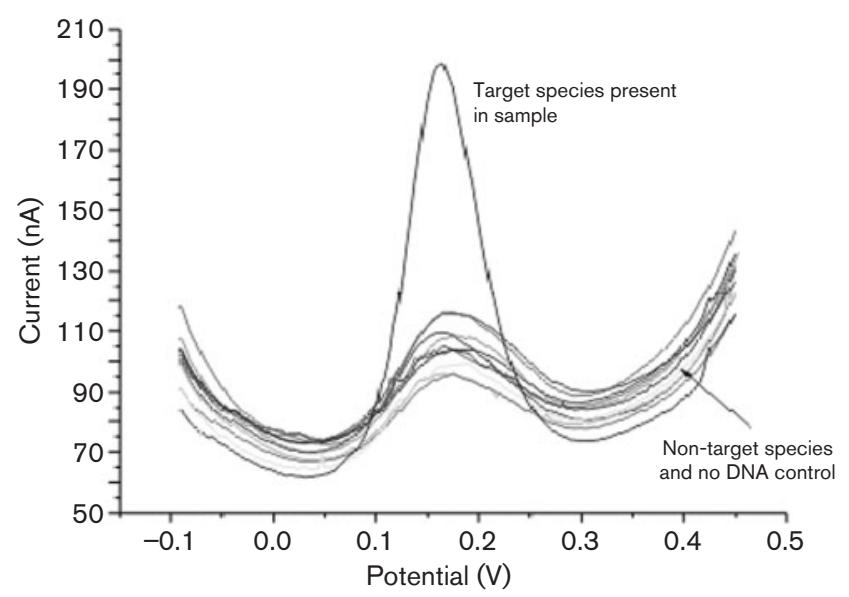

Fig. 1. Electrochemical traces obtained by the probe CT PR tested against 10 Candida species and a DNA-free sample. The current produced in the assay is represented by the peak height. The large peak corresponded to the assay with Candida tropicalis DNA present, whilst the other peaks corresponded to the nontarget species and the DNA-free sample. 


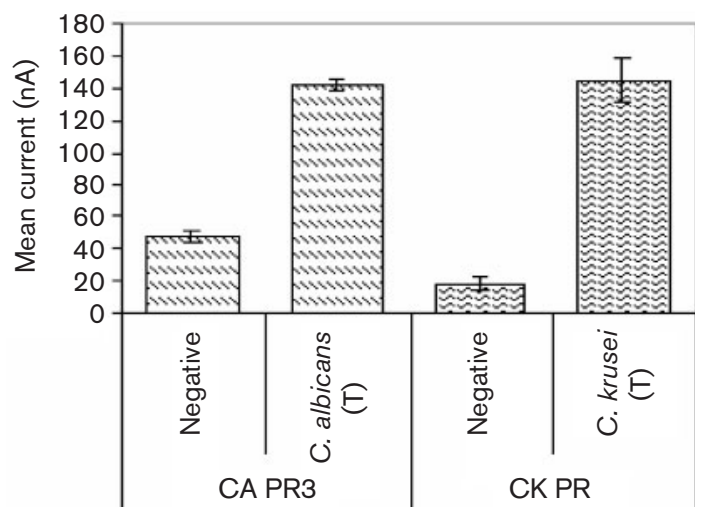

Fig. 2. Example mean currents obtained with the target type species and a DNA-free sample with the Candida albicans- and Candida krusei-specific probes CA PR3 and CK PR. Error bars represent SD $(n=3)$.

\section{Testing the fungal probes against human DNA}

Each of the probes was tested against fungal target DNA in the presence of sufficient human DNA to provide approximately the same number of rRNA gene copies as the fungal target. Discrimination was achieved with all probes and the mean currents produced by PanF PR and CK PR, which were the best- and worst-performing probes, respectively, are shown in Fig. 5. In a clinical sample, the ratio of human cells: fungal cells would be of the order of $10^{9}: 1$, but to achieve this ratio experimentally, based on the amount of fungal DNA currently being used in the assay, would have required milligram quantities of human DNA to be added to the reaction, which was not feasible.

\section{Limit of detection}

Fig. 6 shows sample data using an assay with Candida albicans DNA and the corresponding specific probe, which demonstrated that detection of low amounts of genomic DNA was possible. Table 3 shows the mean currents produced from the assays with each of the probes tested against a range of template amounts of target genomic DNA equivalent to $\sim 100, \sim 10$ and $\sim 1$ genomes. The limit of detection of the PanF PR probe was tested using Candida albicans genomic DNA as this species had originally given the lowest mean current out of all of the pathogenic fungi in the test demonstrating the range of fungi detected by this probe (Fig. 4). All of the probes were capable of detecting down to approximately 1 genome equivalent of DNA. The assay conditions were modified substantially to achieve a limit of detection of 1 genome equivalent and the changes resulted in the DNA-free samples producing no visible peaks in the assay with concomitant zero current with all of the replicates. Furthermore, the changes resulted in higher currents in these assays with picogram amounts of DNA compared with nanogram amounts of DNA in the initial specificity work. The dose response was observed to be highly reproducible but non-linear, the reasons for which were not studied.

The results showed that the electrochemical assay was capable of detecting and identifying fungi to the species level using Candida species-specific probes and that DNA from a broad range of fungal species could be detected using the panfungal probe. The probes were shown to be specific for their target species when tested against a panel of nine other clinically relevant Candida species and were

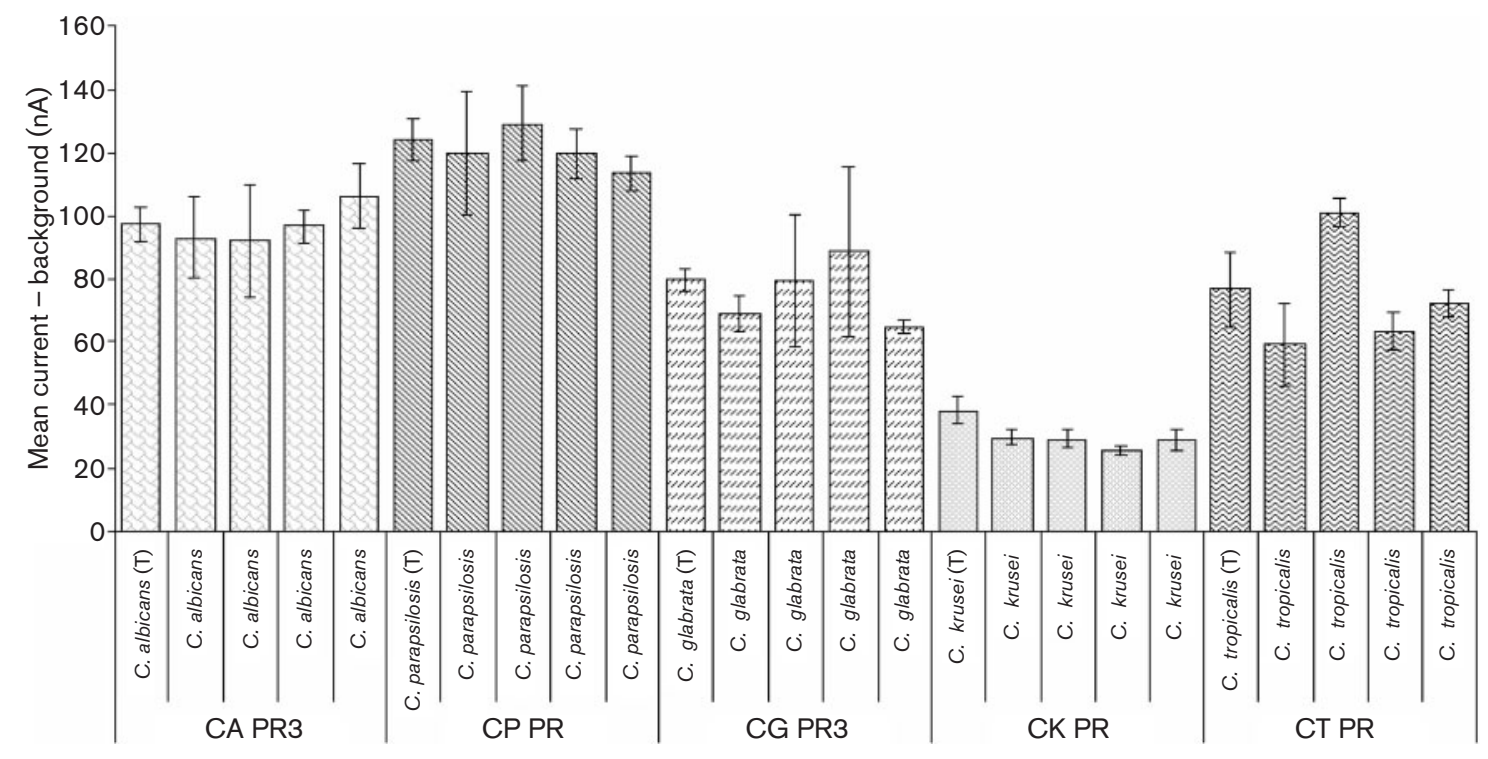

Fig. 3. Mean currents obtained from assays using the type strain and four clinical isolates with all of the Candida speciesspecific probes. Error bars represent SD $(n=3)$. 


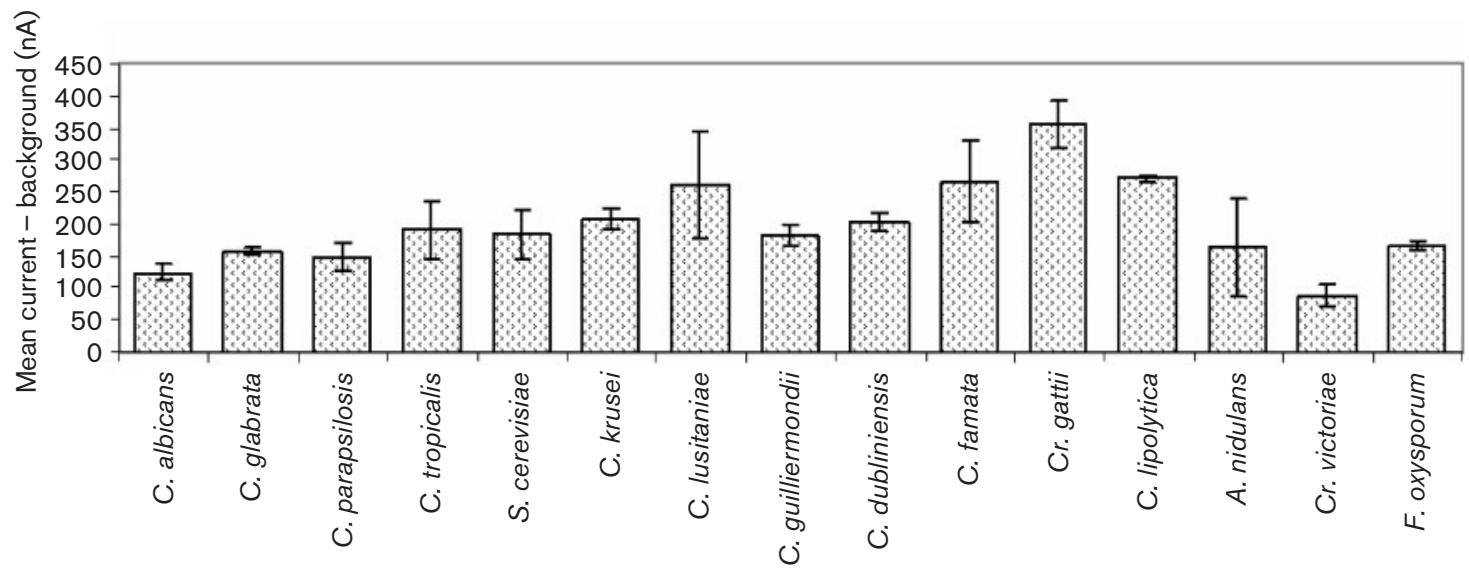

Fig. 4. Example mean currents produced when a range of fungal species were tested with the panfungal PanF PR probe. Error bars represent SD $(n=3)$. The species Cryptococcus victoriae has not been reported as a pathogen of humans.
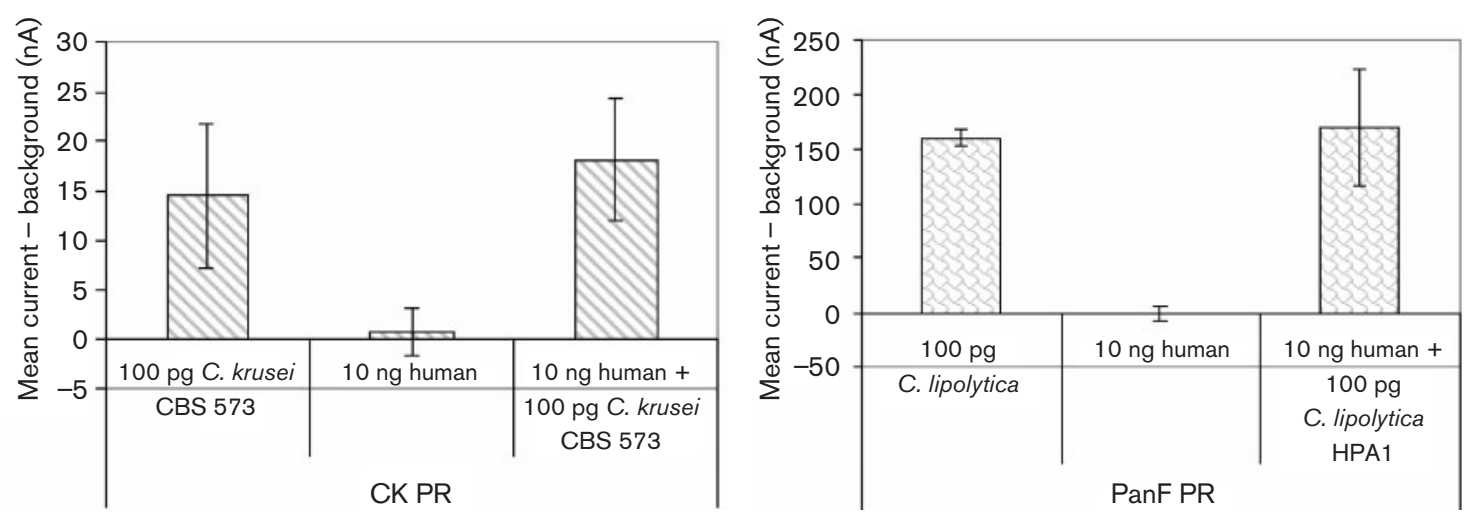

Fig. 5. Example mean currents obtained from assays with the Candida krusei species-specific probe CK PR and the panfungal probe PanF PR testing samples containing human DNA and mixed human and fungal DNA. The Candida krusei type strain was used with the CK PR probe and a clinical strain of Candida lipolytica was used with the PanF PR probe. Note the difference between the scales of the $y$-axis. Error bars represent SD $(n=3)$.
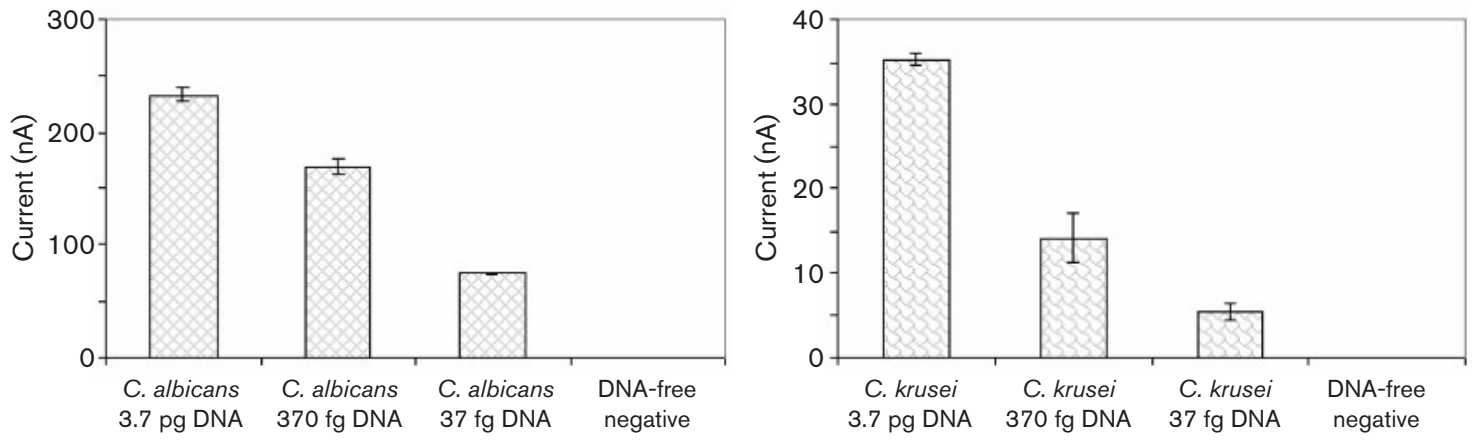

Fig. 6. Example mean currents obtained in assays with $\sim 100, \sim 10$ and $\sim 1$ genome equivalents of Candida albicans and Candida krusei genomic DNA and the probes CA PR3 and CK PR, respectively. Note the difference between the scales of the $y$-axis. Error bars represent SD $(n=3)$. 
Table 3. Mean currents \pm SD $(n=3)$ obtained in assays with 100,10 and 1 fungal genome equivalents with the species-specific probes and the PanF PR probe

\begin{tabular}{|lccc|}
\hline Species and probe used & $\begin{array}{c}\text { Mean current with } \sim \mathbf{1 0 0} \text { genome } \\
\text { equivalents }(\mathbf{n A})\end{array}$ & $\begin{array}{c}\text { Mean current with } \sim \mathbf{1 0} \text { genome } \\
\text { equivalents (nA) }\end{array}$ & $\begin{array}{c}\text { Mean current with } \sim \mathbf{1} \text { genome } \\
\text { equivalent (nA) }\end{array}$ \\
\hline C. albicans - CA PR3 & $233.7 \pm 6.0$ & $169.7 \pm 7.4$ & $74.6 \pm 0.7$ \\
C. parapsilosis - CP PR & $228.3 \pm 40.7$ & $119.8 \pm 21.3$ & $51.6 \pm 15.7$ \\
C. glabrata - CG PR3 & $130.7 \pm 6.5$ & $92.8 \pm 15.8$ & $38.5 \pm 7.2$ \\
C. tropicalis - CT PR & $86.3 \pm 11.1$ & $41.8 \pm 9.3$ & $15.3 \pm 2.7$ \\
C. krusei - CK PR & $35.4 \pm 0.7$ & $14.1 \pm 2.9$ & $4.8 \pm 0.7$ \\
C. albicans - PanF PR & $188.7 \pm 58.0$ & $121.7 \pm 11.1$ & $40.4 \pm 12.8$ \\
\hline
\end{tabular}

able to detect clinical isolates of the relevant target species. The limit of detection for the species-specific probes was demonstrated to be $\sim 1$ genome equivalent.

The PanF PR probe was designed to be able to detect a wide range of fungal pathogens including emerging opportunistic fungi, such as Rhizomucor, Absidia, Fusarium and Penicillium species, as well as the more commonly occurring Cryptococcus, Aspergillus and Candida species. It successfully detected 14 species of opportunistic fungal pathogens, including several infrequently encountered species, and one non-pathogenic fungal species, Cryptococcus victoriae. Using DNA from Candida albicans, the limit of detection of the probe was shown to be $\sim 1$ genome equivalent.

The probe set was designed to detect DNA from any fungal pathogen, as well as to achieve species-specific detection of the most common species involved in invasive fungal infections including Candida glabrata and Candida krusei, which are associated with decreased susceptibility to fluconazole. Detection methods that permit species-specific detection of the most common fungal pathogens, including fluconazole-resistant species, are generally unsatisfactory as they cannot detect infecting species outside the test panel, and the majority of methods of detecting invasive fungal infections have concentrated on a few common fungi, usually Candida species (Shin et al., 1999; Maaroufi et al., 2003; Baskova et al., 2007; Innings et al., 2007; Metwally et al., 2007). Only a few methods have attempted to achieve detection (but not identification) of a range of fungal species (e.g. Vollmer et al., 2008) and very few have tried to design a probe capable of detecting all pathogenic fungi (e.g. Zhao et al., 2009). The inclusion of a panfungal probe in this suite means that early detection of an invasive infection caused by any fungal pathogen could be achieved, enabling a patient to be monitored and treated more successfully. A potential drawback to the use of a highly sensitive panfungal probe is that it necessitates extremely careful handling of samples as it can detect a single cell and thus fungi present in the environment may be detected by the assay.

Multiplex capability is an attractive feature of detection assays as it reduces the number of tests that need to be performed to achieve detection with all of the probes.
Multiplex detection in this assay is currently limited by the number of different ferrocene compounds available, as well as by the need for internal positive controls. The development of unique ferrocene labels for the probes in the fungal suite would be desirable, enabling the probes to be used simultaneously in a single reaction.

In summary, the data show that the described methodology and probes used in this novel detection system have the required specificity and sensitivity to detect fungal DNA at clinically relevant levels and to identify individual species.

\section{ACKNOWLEDGEMENTS}

We would like to thank Donna MacCallum of the University of Aberdeen, UK, Richard Barton of Leeds General Infirmary, UK, Robin May of the University of Birmingham, UK, and Chris Linton of the Health Protection Agency, UK, for donation of fungal strains and DNA. Alastair Muir is in receipt of a Biotechnology and Biological Sciences Research Council Cooperative Award in Science and Engineering with Atlas Genetics Limited.

\section{REFERENCES}

Altschul, S. F., Madden, T. L., Schäffer, A. A., Zhang, J., Zhang, Z., Miller, W. \& Lipman, D. J. (1997). Gapped BLAST and PSI-BLAST: a new generation of protein database search programs. Nucleic Acids Res 25, 3389-3402.

Arendrup, M. C., Fuursted, K., Gahrn-Hansen, B., Schønheyder, H. C., Knudsen, J. D., Jensen, I. M., Bruun, B., Christensen, J. J. \& Johansen, H. K. (2008). Semi-national surveillance of fungaemia in Denmark 2004-2006: increasing incidence of fungaemia and numbers of isolates with reduced azole susceptibility. Clin Microbiol Infect 14, 487-494.

Badiee, P., Kordbacheh, P., Alborzi, A., Malekhoseini, S., Ramzi, M., Mirhendi, H., Mahmoodi, M. \& Shakiba, E. (2009). Study on invasive fungal infections in immunocompromised patients to present a suitable early diagnostic procedure. Int J Infect Dis 13, 97-102.

Baskova, L., Landlinger, C., Preuner, S. \& Lion, T. (2007). The PanAC assay: a single-reaction real-time PCR test for quantitative detection of a broad range of Aspergillus and Candida species. J Med Microbiol 56, 1167-1173.

Clancy, C. J., Nguyen, M. L., Cheng, S., Huang, H., Fan, G., Jaber, R. A., Wingard, J. R., Cline, C. \& Nguyen, M. H. (2008). Immunoglobulin $\mathrm{G}$ responses to a panel of Candida albicans antigens as accurate and early markers for the presence of systemic candidiasis. J Clin Microbiol 46, 1647-1654. 
Fujita, S., Lasker, B. A., Lott, T. J., Reiss, E. \& Morrison, C. J. (1995). Microtitration plate enzyme immunoassay to detect PCR-amplified DNA from Candida species in blood. J Clin Microbiol 33, 962-967.

Garey, K. W., Rege, M., Pai, M. P., Mingo, D. E., Suda, K. J., Turpin, R. S. \& Bearden, D. T. (2006). Time to initiation of fluconazole therapy impacts mortality in patients with candidemia: a multiinstitutional study. Clin Infect Dis 43, 25-31.

Hajjeh, R. A., Sofair, A. N., Harrison, L. H., Lyon, G. M., ArthingtonSkaggs, B. A., Mirza, S. A., Phelan, M., Morgan, J., Lee-Yang, W. \& other authors (2004). Incidence of bloodstream infections due to Candida species and in vitro susceptibilities of isolates collected from 1998 to 2000 in a population-based active surveillance program. J Clin Microbiol 42, 1519-1527.

Hata, D. J., Buckwalter, S. P., Pritt, B. S., Roberts, G. D. \& Wengenack, N. L. (2008). Real-time PCR method for detection of zygomycetes. J Clin Microbiol 46, 2353-2358.

Hillier, S. C., Flower, S. E., Frost, C. G., Jenkins, A. T. A., Keay, R., Braven, H., Flower, S. E. \& Clarkson, J. M. (2004). An electrochemical gene detection assay utilising T7 exonuclease activity on complementary probe-target oligonucleotide sequences. Electrochem Commun 6, 1227-1232.

Horn, D., Neofytos, D., Fishman, J., Steinbach, W., Anaisie, E., Marr, K. A., Pfaller, M. \& Olyaei, A. (2007). Use of the PATH Alliance database to measure adherence to IDSA guidelines for the therapy of candidemia. Eur J Clin Microbiol Infect Dis 26, 907-914.

Innings, A., Ullberg, M., Johansson, A., Rubin, C. J., Noreus, N., Isaksson, M. \& Herrmann, B. (2007). Multiplex real-time PCR targeting the RNase P RNA gene for detection and identification of Candida species in blood. J Clin Microbiol 45, 874-880.

Kao, A. S., Brandt, M. E., Pruitt, W. R., Conn, L. A., Perkins, B. A., Stephens, D. S., Baughman, W. S., Reingold, A. L., Rothrock, G. A. \& other authors (1999). The epidemiology of candidemia in two United States cities: results of a population-based active surveillance. Clin Infect Dis 29, 1164-1170.

Kerr, C. \& Sadowski, P. D. (1972). Gene 6 exonuclease of bacteriophage T7. II. Mechanism of the reaction. J Biol Chem 247, 311-318.

Kullman, B., Tamm, H. \& Kullman, K. (2005). Fungal genome size database. http://www.zbi.ee/fungal-genomesize. Accessed 15/03/2009.

Lau, A., Sorrell, T. C., Chen, S., Stanley, K., Iredell, J. \& Halliday, C. (2008). Multiplex tandem PCR: a novel platform for rapid detection and identification of fungal pathogens from blood culture specimens. J Clin Microbiol 46, 3021-3027.

Linton, C. J., Borman, A. M., Cheung, G., Holmes, A. D., Szekely, A., Palmer, M. D., Bridge, P. D., Campbell, C. K. \& Johnson, E. M. (2007). Molecular identification of unusual pathogenic yeast isolates by large ribosomal subunit gene sequencing: 2 years of experience at the United Kingdom Mycology Reference Laboratory. J Clin Microbiol 45, $1152-1158$.
Maaroufi, Y., Heymans, C., De Bruyne, J. M., Duchateau, V., Rodriguez-Villalobos, H., Aoun, M. \& Crokaert, F. (2003). Rapid detection of Candida albicans in clinical blood samples by using a TaqMan-based PCR assay. J Clin Microbiol 41, 3293-3298.

Metwally, L., Hogg, G., Coyle, P. V., Hay, R. J., Hedderwick, S., McCloskey, B., O'Neill, H. J., Ong, G. M., Thompson, G. \& other authors (2007). Rapid differentiation between fluconazole-sensitive and -resistant species of Candida directly from positive blood-culture bottles by real-time PCR. J Med Microbiol 56, 964-970.

Pfaller, M. A., Diekema, D. J., Gibbs, D. L., Newell, V. A., Bijie, H., Dzierzanowska, D., Klimko, N. N., Letscher-Bru, V., Lisalova, M. \& other authors (2009). Results from the ARTEMIS DISK Global Antifungal Surveillance Study, 1997 to 2007: a 10.5-year analysis of susceptibilities of noncandidal yeast species to fluconazole and voriconazole determined by CLSI standardized disk diffusion testing. J Clin Microbiol 47, 117-123.

Shin, J. H., Nolte, F. S. \& Morrison, C. J. (1997). Rapid identification of Candida species in blood cultures by a clinically useful PCR method. J Clin Microbiol 35, 1454-1459.

Shin, J. H., Nolte, F. S., Holloway, B. P. \& Morrison, C. J. (1999). Rapid identification of up to three Candida species in a single reaction tube by a $5^{\prime}$ exonuclease assay using fluorescent DNA probes. J Clin Microbiol 37, 165-170.

Tamura, K., Dudley, J., Nei, M. \& Kumar, S. (2007). MEGA4: Molecular Evolutionary Genetics Analysis (MEGA) software version 4.0. Mol Biol Evol 24, 1596-1599.

Tortorano, A. M., Peman, J., Bernhardt, H., Klingspor, L., Kibbler, C. C., Faure, O., Biraghi, E., Canton, E., Zimmermann, K. \& other authors (2004). Epidemiology of candidaemia in Europe: results of 28-month European Confederation of Medical Mycology (ECMM) hospital-based surveillance study. Eur J Clin Microbiol Infect Dis 23, 317-322.

van Deventer, A. J., Goessens, W. H., van Belkum, A., van Vliet, H. J., van Etten, E. W. \& Verbrugh, H. A. (1995). Improved detection of Candida albicans by PCR in blood of neutropenic mice with systemic candidiasis. J Clin Microbiol 33, 625-628.

Vollmer, T., Störmer, M., Kleesiek, K. \& Dreier, J. (2008). Evaluation of novel broad-range real-time PCR assay for rapid detection of human pathogenic fungi in various clinical specimens. $J$ Clin Microbiol 46, 1919-1926.

White, T. J., Burns, T. D., Lee, S. B. \& Taylor, J. W. (1990). Amplification and direct sequencing of fungal ribosomal RNA genes for phylogenetics. In PCR Protocols: A Guide to Methods and Applications, pp. 315-322. Edited by M. A. Innis, D. H. Gelfand, J. J. Sninsky \& T. J. White. San Diego, CA: Academic Press.

Zhao, Y., Park, S., Kreiswirth, B. N., Ginnochio, C. C., Veyret, R., Laayoun, A., Troesch, A. \& Perlin, D. S. (2009). A rapid real-time nucleic acid sequence-based amplification (NASBA)-molecular beacons platform to detect fungal and bacterial bloodstream infections. $J$ Clin Microbiol (in press). 